\title{
Review of Outcome Information in 46,XX Patients with Congenital Adrenal Hyperplasia Assigned/Reared Male: What Does It Say about Gender Assignment?
}

\author{
Peter A. Lee ${ }^{1,2}$ and Christopher P. Houk ${ }^{3}$ \\ ${ }^{1}$ Department of Pediatrics, MC H085, Penn State College of Medicine, The Milton S. Hershey Medical Center, P.O. Box 850, \\ 500 University Drive, Hershey, PA 17033-0850, USA \\ ${ }^{2}$ Section of Pediatric Endocrinology, Riley Hospital for Children, Indiana University School of Medicine, Indianapolis, IN 46202, USA \\ ${ }^{3}$ Department of Pediatrics, Medical College of Georgia, Augusta, GA 30912, USA
}

Correspondence should be addressed to Peter A. Lee, leepa@iupui.edu

Received 14 May 2010; Revised 14 October 2010; Accepted 26 November 2010

Academic Editor: John Fuqua

Copyright (๑) 2010 P. A. Lee and C. P. Houk. This is an open access article distributed under the Creative Commons Attribution License, which permits unrestricted use, distribution, and reproduction in any medium, provided the original work is properly cited.

\begin{abstract}
There is ample historical verification of 46,XX congenital adrenal hyperplasia (CAH) patients being born with essentially male genitaliawhile outcome information is scant. Prior to glucocorticoid therapy, most patients died very young from adrenal insufficiency. Most available reports from laterchildhood, contain little information concerning sexual identity. Reports on older individuals lack adequate information about sexual identity and quality of life. The difficulty in assessing the relative impact of multiple dynamic environmental factors on the development of sexual identity, self- and body esteem and overall adjustment to life is clear. Nevertheless, it remains unclear whether those infants whose masculine genitalia at birth resulted in an initial male assignment would have enjoyed a better adult outcome had they been allowed to remain male rather than the female reassignment that most received. Further, one could ask whether a male sex of rearing should be considered in 46,XX CAH infants with male external genitalia. After reviewing available literature, we conclude that because those extremely virlized 46,XX CAH patients who were reared male with healthy social support demonstrated satisfactory levels of social and sexual function as adults a male sex assignment should be considered in these types of infants when social and cultural environment are supportive.
\end{abstract}

\section{Background}

The virilizing forms of 21-hydroxylase and 11-hydroxylase deficiency CAH manifest a complete spectrum of virilization in 46,XX individuals ranging from none to complete virilization such that in rare cases the external genitalia are entirely male with absent testes. When this diagnosis of $\mathrm{CAH}$ is recognized in infancy, the recommendation for sex of rearing-even in those with fully virilized external genitalia-has been categorically female. The support for this dogmatic approach revolves around the preservation of fertility; that is, because there are ovaries and a uterus, a female assignment is justified. This recommendation stems from the outcome data that show that with appropriate therapy, normal female growth, development, and fertility, and, a female sexual identity can be reasonably anticipated with a female sex assignment. However, these outcome data have also been disappointing in some respects, particularly in those who were markedly virilized at birth $[1,2]$. It is important to point out the similarities of this reasoning to the rationale present in the optimal gender approach used beginning in the 1950's to guide sex assignment in DSD infants. Although almost all ( 95\%) 46,XX CAH infants develop a female gender identity as adults, a sizable number have difficulty establishing intimate relationships and fertility is markedly reduced $[3,4]$. While gender role behavior and sexual orientation should not be considered as evidence of treatment failure, a larger portion of these $\mathrm{CAH}$ patients are homo- or bisexual compared with the general population [5]. The role played by prenatal androgen exposure on the developing brain and its relationship to outcomes in CAH patients remains unclear, but the evidence 
supporting a relationship between androgen and brain development is irrefutable [5]. The available outcome data on sexual identity in 46,XX CAH patients cited throughout this paper suggests that it may be related to the variable degrees of virilization of the external genital seen in this disorder, and it is therefore counterintuitive to propose that all 46,XX CAH infants be managed identically regardless of degree of genital virilization.

While rare, the percentage of $46, \mathrm{XX}$ patients with $\mathrm{CAH}$ born with Prader 4-5 genitalia is unknown, and it would be expected to occur more commonly in those patients harboring mutations causing severe enzyme deficiency. Further, since reports of gender assignment do not clearly indicate what portion were born with Prader 4-5 genitalia, the historical percentage of this subgroup of $\mathrm{CAH}$ infants who are reared male versus female is unknown. Further, it is impossible to ascertain surgical histories. However, since this surgical history is both incomplete and likely not representative of modern surgical approaches history, it should have little bearing on considerations for the future care. Using modern surgical techniques, virilized 46,XX $\mathrm{CAH}$ infants would need only one procedure to remove internal structures, correct hypospadias/chordee, and to place prosthetic testes if desired.

In this report, we attempt to separate this unique group of virilized $\mathrm{CAH}$ infants and present what is known about their outcomes. In the last year, we have reported our experience with a group of 46,XX male CAH patients. This report described 12 adult 46,XX CAH males, all of whom have a male gender identity and were sexually attracted to females, 10 of whom had always been reared male, as well as a group of four 46,XX infants whose parents chose a male sex assignment (after full disclosure) even after the diagnosis of $\mathrm{CAH}$ in the neonatal period. It was during the preparation of the paper about the 12 adult $\mathrm{CAH}$ males [6] that we found extensive literature regarding other similar patients and decided to prepare this review. This literature review included searching for information on severely virilized 46,XX CAH patients on PubMed, general internet, and traditional library searches, old and current endocrinology textbooks, followed by locating references of earlier publications cited in located publications.

\section{Literature Review}

Historically, the diagnosis of CAH in those rare individuals with Prader 4 or 5 external genitalia has been delayed in spite of clinical evidence of adrenal crisis (Table 1) [7]. Especially prior to the availability of glucocorticoid therapy, the diagnosis was often made at autopsy following a death from adrenal insufficiency [8]. In others, the diagnosis of $\mathrm{CAH}$ was made during the assessment of presumed cryptorchidism, gynecomastia, or hematuria. Previously it was recommended that these patients be reassigned female when the diagnosis was made during childhood. More recently, however, it has been recognized that gender identity appears to be established in the first several years of life [9] and that gender reassignment may be harmful. This practice has provided a small group of 46,XX CAH adult males whose quality of life can now be assessed.

Those patients listed in Table 1 include patients whose genitalia were essentially male at birth, having fully fused labia with the penile urethra being at the tip of the glans or distally on the underside of the penis (Prader stage 4 or 5 ). While there are several reports, these are essentially case reports and do not involve systematic assessment of subjects but rather descriptions of presentation and natural history. Many details are lacking, particularly regarding evidence of gender dysphoria. Hence, it is impossible to clearly substantiate outcome data. Table 1(a) consists of patients who died from adrenal insufficiency in infancy. Table 1(b) lists those reared male but reported during childhood so that long-term outcome data are not available. Table 1(c) lists patients reassigned female including some for whom outcome data is known. Table $1(\mathrm{~d})$ includes patients reared male who were reported during adulthood; within this later group are the most informative outcome data summarized below. The attempt is to review outcome information, with a focus on outcomes in patients born with male genitalia, requiring little to no genital surgery. There are additional reports of patients born with genital ambiguity who had gender dysphoria who declared a male gender in adulthood. This later group constitutes a different situation than the sexual identity issues seen in the nonambiguous primary group reported here.

\section{Review of Recommendation for Gender Assignment}

The standard of care for 46,XX CAH patients diagnosed in infancy has been to recommend a female gender assignment and sex of rearing. This standard is based on the idea that these patients are really female-as defined by karyotypeand the benefit of preserving fertility outweighs a small risk of future gender dysphoria or dysfunctional sexual function resulting from surgery. The expectation has been that, with appropriate medical care of adrenal hyperplasia, growth, puberty, sexuality, and reproduction would be similar to unaffected females. Historically, even 46,XX CAH patients with male external genitalia were felt to have a reasonable expectation of fertility. However, while fertility rates in many 46,XX CAH patients are only slightly impaired, the fertility rate of severely virilized CAH patients is strikingly low [3]. This generation of patients also underwent feminizing surgery that often damaged the neurovascular supply of the external genitalia, thereby precluding normal sexual responsiveness. While it is hoped that modern surgical techniques reduce the risk of neurovascular damage, it is likely that other factors also influence sexuality and fertility in these patients.

In the case of the fully virilized 46,XX CAH patient, a male sex of rearing minimizes the need for external genital surgery (other than placement of prosthetic testes), and the outcome in these patients showing sufficient male sexual function suggests that satisfactory adult sexual activity is possible. Given the high rates of male gender identity and 
TABLE 1: 46,XX* CAH patients with male external genitalia assigned/reared male.

(a) Death during infancy, most with evidence of adrenal insufficiency.

\begin{tabular}{lll}
\hline Year & First author & Reference \\
\hline (1) 1896 & Krokiewicz & Virchow's Arch path Anat Physiol \\
(2) 1905 & Fibiger & $146: 525$ \\
(3) 1914 & Benda & Virchow's Arch path Anat $181: 1$ \\
(4) 1919 & Lehmann & Berlin klin. Wschr $51: 66$ \\
(5) 1947 & Allibone & Ugesk. Laeger $81: 751$ \\
(6) 1952 & Marie & Arch Dis Child $22: 210$ \\
(7) 1953 & Perloff & Arch franc pediat $9: 785$ \\
(8) 1954 & Matheson & J Clin Endocrinol $13: 78$ \\
(9) 1961 & Rook & Arch Dis Child $29: 22$ \\
\hline
\end{tabular}

(b) Diagnosed and reported during childhood, reared male.

\begin{tabular}{|c|c|c|c|}
\hline Year & First author & Reference & Age of diagnosis \\
\hline (1) 1955 & Gross & Pediatrics $16: 303$ & $?$ \\
\hline (2) 1956 & Bentinck & J Clin Endocrinol Metab 16:412 & 2 years \\
\hline (3) 1957 & Wilkins & Dx and Rx of Endocrine Disorders, 2nd & 7.5 years \\
\hline (4) 1958 & Prader & Helv Paediatr Acta $13: 5$ & 4 years \\
\hline (5) 1966 & Weldon & N Engl J Med 274 : 829 & 2.5 years \\
\hline (6) 1966 & Weldon & N Engl J Med 274: 829 & 3.5 years \\
\hline (7) 1972 & Redman & J Urol 108:500 & 6 years \\
\hline (8) 1976 & Money & J Homosex $1: 357$ & 1 month \\
\hline (9) 1976 & Money & J Homosex $1: 357$ & 12 years \\
\hline (10) 1970 & Gillenwater & J Urol $103: 500$ & 4 years \\
\hline (11) 1987 & Wyatt & J Pediatr Endocrinol 2:35 & 3.6 years \\
\hline (12) 1984 & Rösler & Adrenal Disease in Childhood $13: 47$ & 1.9 years \\
\hline (13) 1984 & Rösler & Adrenal Disease in Childhood 13:47 & 1 year \\
\hline (14) 1984 & Rösler & Adrenal Disease in Childhood $13: 47$ & 1.6 years \\
\hline (15) 1984 & Rösler & Adrenal Disease in Childhood $13: 47$ & 2 years \\
\hline (16) 1989 & Chan-Cua & Amer J Med Genetics 34:406 & 8.2 years \\
\hline (17) 1989 & Chan-Cua & Amer J Med Genetics $34: 406$ & 4.3 years \\
\hline (18) 1997 & Sripathi & Brit J Urol 79: 785 & 10 years \\
\hline (19) 1997 & Sripathi & Brit J Urol 79: 785 & 4 years \\
\hline (20) 1997 & Sripathi & Brit J Urol 79: 785 & 7 years \\
\hline (21) 1997 & Sripathi & Brit J Urol 79: 785 & 11 years \\
\hline (22) 1997 & Sripathi & Brit J Urol 79: 785 & 3.5 years \\
\hline (23) 1997 & Sripathi & Brit J Urol 79:785 & 16.6 years \\
\hline (24) 2002 & Woelfle & Clin Endocrinol $56: 231$ & 3.5 years \\
\hline (25) 2002 & Woelfle & Clin Endocrinol 56:231 & 4.5 years \\
\hline (26) 2002 & Woelfle & Clin Endocrinol 56:231 & 7 years \\
\hline
\end{tabular}

(c) Diagnosed during infancy or childhood with reassignment.

\begin{tabular}{llll}
\hline Year & First author & Reference & Age of reassignment \\
\hline$(1) 1958$ & Ainger & AMA J Dis Child 95:410 & 3 years \\
(2) 1965 & Wiedemann & Monatsschr Kinderheilkd 113:434 & 14 months \\
\hline
\end{tabular}


(c) Continued.

\begin{tabular}{|c|c|c|c|}
\hline Year & First author & Reference & Age of reassignment \\
\hline (3) 1966 & Weldon & N Engl J Med 274: 829 & 3 weeks \\
\hline (4) 1966 & Weldon & N Engl J Med 274: 829 & 8 weeks** \\
\hline (5) 1966 & Weldon & N Engl J Med 274: 829 & 11 months \\
\hline (6) 1969 & Rosenberg & N Eng J Med $280: 131$ & 3 weeks \\
\hline (7) 2002 & Woelfle & Clin Endocrinol 56:231 & 2 days \\
\hline (8) 2002 & Woelfle & Clin Endocrinol $56: 231$ & 1 month \\
\hline (9) 2002 & Woelfle & Clin Endocrinol 56:231 & 1 month \\
\hline (10) 2002 & Woelfle & Clin Endocrinol 56:231 & 1 month \\
\hline (11) 2002 & Woelfle & Clin Endocrinol 56:231 & 1 month \\
\hline (12) 2002 & Woelfle & Clin Endocrinol 56:231 & 19 months \\
\hline (13) 2002 & Woelfle & Clin Endocrinol 56:231 & 7 years \\
\hline (14) 2002 & Woelfle & Clin Endocrinol 56:231 & 9 years \\
\hline (15) 2002 & Woelfle & Clin Endocrinol 56:231 & 11 Years \\
\hline (16-24) 2006 & Gupta & Pediatr Surg Int 22: 905 & not stated \\
\hline
\end{tabular}

(d) Diagnosed during childhood, reared male, reported $>17$ years.

\begin{tabular}{|c|c|c|c|}
\hline Year & First author & Reference & Age at report \\
\hline (1) 1960 & Peris & Obstet Gynecol 16:156 & 18 years \\
\hline (2) 1963 & Madsen & J Urol $90: 446$ & 35 years \\
\hline (3) 1963 & Madsen & J Urol $90: 446$ & 30 years \\
\hline (4) 1965 & Maxted & J Urol $94: 266$ & 21 years \\
\hline (5) 1976 & Money & J Homosex $1: 357$ & adult \\
\hline (6) 1976 & Money & J Homosex $1: 357$ & adult \\
\hline (7) 1978 & Kiviat & Urol $12: 75$ & 17 years \\
\hline$(8-15) 1984$ & Rösler & Adrenal Disease in Childhood 13:47 & $17-33$ years \\
\hline (16) 2002 & Woelfle & Clin Enocrinol $56: 231$ & 36 years \\
\hline (17) 2002 & Woelfle & Clin Enocrinol 56:231 & 31 years \\
\hline (18) 2002 & Woelfle & Clin Enocrinol 56:231 & 50 years \\
\hline (19) 2002 & Woelfle & Clin Enocrinol $56: 231$ & 24 years \\
\hline (20) 2004 & Jones & J Pediatr Endocrinol Metab & Died at 31 years \\
\hline (21) 2010 & Lee & J Urol 184 (suppl 4): 1786 & 35 years \\
\hline (22) 2010 & Lee & J Urol 184 (suppl 4): 1786 & 36 years \\
\hline (23) 2010 & Lee & J Urol 184 (suppl 4): 1786 & 45 years \\
\hline (24) 2010 & Lee & J Urol 184 (suppl 4): 1786 & 46 years \\
\hline (25) 2010 & Lee & J Urol 184 (suppl 4): 1786 & 47 years \\
\hline (26) 2010 & Lee & J Urol 184 (suppl 4): 1786 & 49 years \\
\hline (27) 2010 & Lee & J Urol 184 (suppl 4): 1786 & 49 years \\
\hline (28) 2010 & Lee & J Urol 184 (suppl 4): 1786 & 53 years \\
\hline (29) 2010 & Lee & J Urol 184 (suppl 4): 1786 & 57 years \\
\hline (30) 2010 & Lee & J Urol 184 (suppl 4): 1786 & 69 years \\
\hline
\end{tabular}

* for those reported before the ability to determine the presence of an XX karyotype; this karyotype is presumed based upon the presence of differentiation consistent with this, either from autopsy findings or surgical observations.

$* *$ those with reported gender problems.

sexual orientation toward females in 46,XX CAH patients assigned male-with appropriate family support-we propose that it is reasonable to consider a male sex of rearing in the markedly virilized $46, \mathrm{XX} \mathrm{CAH}$ patient, even when diagnosed in the neonate. To support this proposal, outcome information from markedly virilized patients reared male will be reviewed. As noted, early reports often involved patients who died in infancy or childhood due to adrenal 
insufficiency [8]. In others, the diagnosis was made after the child had firmly established a male gender identity and reassignment was not considered. It is from this small group of 46,XX CAH adult males (Table 1(d)) that outcome information is particularly informative.

\section{Report of Gender Outcome, Including but Not Limited to Those Fully Masculinized}

In 2005, a literature review of gender identity, gender change and gender dysphoria in 46,XX CAH patients included 250 subjects with varying amounts of masculinization of external genitalia reared female and 33 subjects with male genitalia reared male [10]. Age at latest report ranged from 4 to 49 years. Initial sex assignment is not clear for all of the 250 reared female, 24 of whom were initially assigned male. In those 24 initially assigned male, female reassignment occurred in the first 19 months of life for 20 and the remaining 4 were reassigned female between the ages of 3.5 and 9 years of age. Of these 250 reared female, 4 were subsequently reassigned male, including 2 who had been assigned male at birth. A total of 13 had gender dysphoria, including all of the patients reassigned male. Dysphoria was not present in 232 and was not reported for 15 . Hence, among 235,222 or $94.4 \%$ had a female gender identity with no gender dysphoria. Gender identity problems were found in $4.6 \%$, a higher percentage than the $0.008 \%$ found in one country, which may not be representative of the general population [11].

Among the 33 who were initially assigned and reared male, gender dysphoria was found in 4 or $12 \%$. One had gender dysphoria, one had a "disturbed gender identity", one was ambivalent, and one was not adjusted as a male. These 4 ranged in age from 17 to 49 years. While the percentages differ, there simply are inadequate data to conclude that there is a difference regarding gender problems among $\mathrm{CAH}$ patients reared male or female. It is noteworthy that gender problems were reported only for those over 17 years of age, forming the rationale for our focus on subjects aged 17 years or older.

This report illustrates the complexities of attempting to make meaningful conclusions because degree of virilization, age of gender assignment and reassignment, and evidence for gender dysphoria were not systematically assessed. Among the 13 of the 250 reared female reported to have gender dysphoria, severity of masculinization at birth was not indicated for 5, and initial gender assignment was female for 7. Many of these 250 females were born with lesser degrees of genital virilization in contrast to the 33 subjects initially assigned and reared male, all of whom had essentially male genitalia. Further, gender dysphoria was reported among those of all ages, while gender dysphoria manifest during adulthood is probably stronger evidence. While the authors' conclusion [10] was that there was no basis for a gender assignment other than female for all CAH 46,XX patients, the two groups, those reared female and male, are not comparable given their different numbers, age at assessment, and spectrum of masculinization.

\section{Small Series of Outcome Information}

While the authors of the above report conclude that the general policy of assigning severely masculinized 46,XX CAH patients female is justified, we would disagree based on the fact that the outcome data, which did not consistently report the degree of virilization, was insufficient to allow the degree of virilization to be compared with the outcome measures used. To be fair, we do not feel that this report presents enough data to recommend a male assignment either. However, the following citations of available adult outcome data, although scant, are adequate to suggest male gender identity, satisfactory sexual function, and an expectation of sexual orientation toward females in those severely virilized 46,XX CAH patients who were assigned male. These factors together with the differences in the extent and consequences (fertility, sexual function) of surgical repair required for female assignment need to be considered when making the decision to raise a child in the male or female sex.

5.1. Age and Determinants of Gender Components. It is of interest that fully virilized 46,XX CAH individuals develop an apparently clear male gender identity during infancy, at the age when gender identity is expected to occur [9]. However, the relative influence of other factors, including prenatal androgen exposure [12] and other cultural influences, including being treated by parents and others as a male, remains unclear [13].

Although correlative animal studies suggest that neuroendocrine mechanisms of differentiation of neural circuits are involved in sexual partner preference (sexual orientation), applicability to human gender identity and sexual orientation is unclear [14]. Prenatal and neonatal brain exposure to androgens may play a role in human sexual behavior, no impact on gender identity is known. In fact, evidence suggests that the initial gender assignment remains the best indicator of adult gender identity [15], a factor that must be considered for the markedly virilized 46,XX CAH patient assigned male.

\section{Reports Vary by Age and Completeness of Assessment}

Further review of reports of those with essentially complete male virilization includes the several studies that report subjects less than 17 years of age: two at 3.5 years of age and 12 years of age [16], another two 46,XX Prader 5 patients reared male without gender problems who were diagnosed during evaluation for cryptorchidism [7], six patients (including 2 brothers) diagnosed at birth but reared as male at parents insistence, who had no recognized evidence of gender problems at ages 3 to 16 years [17], and 3 Prader 5 patients assigned male continued to live as males when reported (aged 11-16 years) with one who expressing concern about "living as a male" [18].

In a series from Saudi Arabia, 6 of 51 46,XX CAH children underwent gender reversal and were managed as males [16]. The choice was based primarily on parents' 
input, with 4 of the 6 having delayed diagnosis. All had gonadectomy and excision of Müllerian-derived structures; 2 received circumcision/hypospadias repair and 4 underwent chordee repair. All were reported to be well adjusted to their sexual status with normal male behavior and activities but none were adults, all aged between 3 to 16 years. Further, it is unclear if any were fully masculinized. This report likely reflects cultural differences in attitudes about gender and sexuality, the role of the sexes in society, and parents' perceptions.

Adult patients ( $>17$ years) included one reared male with Prader 4 genitalia before glucocorticoid therapy and without surgery who had a clear male gender identity, sexual orientation toward females, and an intimate sexual relationship [19], another adult patient who had always lived as a male with no gender issues [20], and four Prader 5 patients originally assigned male who continued to live as males without gender problems (aged 31 to 50 years) [17]. One of these subjects was married and another denied ever having a sexual experience with a partner. For the remainder of those listed in Table $1(\mathrm{~d})$, outcome adjustment is not indicated beyond the fact that they were male.

\section{Fully Masculinized Adult Patients Assigned/Reared Male}

Among twenty adult patients reared male, brief comments were included for 3 with gender problems (Table 1(d)-120). In addition, we have added ten more $46, \mathrm{XX}$ males, aged 35 to 69 years of age who have always lived as male [6]. These men are all prescribed calculated replacement glucocorticoid therapy to provide adequate therapy for daily glucocorticoid needs and suppress sex steroid excess and have been also prescribed replacement testosterone therapy. Although some of these men have had significant adjustment issues and poor family support, all retain a male gender identity with a sexual orientation toward females; 8 were married or had long-term female partners. Thus, while these men were not uniformly assessed, brief comments regarding gender problems or unknown severity were noted in 3 of the 30.

While gender change from female to male has been documented in 46,XX CAH patients [21], the authors are not aware of any instance of gender change from male to female in this group of patients. The available outcome data are not sufficiently complete to allow comparison of outcomes between fully masculinized 46,XX CAH patients reared male versus those reared female, and it is unlikely that such data will be available in the near future given the complexity of the factors needed to accurately assess outcome. The relationship between gender identity and quality of life has not been adequately studied in such situations. Reports of quality of life among chronically ill older patients report inconsistent findings regarding the relationship of quality of life and gender role $[22,23]$, while it is clear that those with gender identity disorders have significant quality-oflife issues $[24,25]$. However, in this situation, there may not be gender dysphoria. Further, it is quite possible that quality of life for the virilized 46,XX CAH patient proceeds from the initial gender assignment, providing the basis for a secure gender identity. This may provide a crucial factor in quality of life. This is consistent with a stable gender identity being an important factor in quality of life. Fortunately, there is some agreement on those outcome factors that should be used to judge quality-of-life outcomes for $46, \mathrm{XX} \mathrm{CAH}$ patients: self esteem, body image, fulfilling interpersonal relationships, harmonious sexual identity (gender identity, sexual experience satisfaction), and fertility. When these factors are measured in 46,XX CAH patients assigned male, the outcome is comparable to those assigned female. In this latter group, those who were most virilized often manifest the worst outcomes.

Hence, we feel that a male gender assignment for the severely virilized patient is worthy of consideration and are advocating for this [26]. Further, we feel the available data provide some compelling reasons to consider a male assignment in some of the severely virilized $46, \mathrm{XX} \mathrm{CAH}$ subjects.

Furthermore, we believe that these specialized cases of 46,XX DSD have something to say about gender assignment in general and for those difficult cases of 46,XY DSD. When considering gender assignment, many factors must be taken into consideration. It would be incorrect to assign gender based upon the presumed dictates of biological variables alone. What needs to be done as illustrated by the cases herein is to weigh all the factors with a focus on what assignment would hopefully provide the best quality of life in the long run.

\section{References}

[1] G. Warne, "Congenital adrenal hyperplasia: long-term outcome studies," Endocrinologist, vol. 13, no. 3, pp. 179-181, 2003.

[2] T. H. Johannsen, C. P. L. Ripa, E. L. Mortensen, and K. M. Main, "Quality of life in 70 women with disorders of sex development," European Journal of Endocrinology, vol. 155, no. 6, pp. 877-885, 2006.

[3] R. M. Mulaikal, C. J. Migeon, and J. A. Rock, "Fertility rates in female patients with congenital adrenal hyperplasia due to 21-hydroxylase deficiency," New England Journal of Medicine, vol. 316, no. 4, pp. 178-182, 1987.

[4] H. F. L. Meyer-Bahlburg, "What causes low rates of childbearing in congenital adrenal hyperplasia?" Journal of Clinical Endocrinology and Metabolism, vol. 84, no. 6, pp. 1844-1847, 1999.

[5] R. W. Dittmann, M. E. Kappes, and M. H. Kappes, "Sexual behavior in adolescent and adult females with congenital adrenal hyperplasia," Psychoneuroendocrinology, vol. 17, no. 23, pp. 153-170, 1992.

[6] P. A. Lee, C. P. Houk, and D. A. Husmann, "Should male gender assignment be considered in the markedly virilized patient with 46,XX and congenital adrenal hyperplasia?" Journal of Urology, vol. 184, supplement 4, pp. 1786-1791, 2010.

[7] S. Chan-Cua, G. Freidenberg, and K. L. Jones, "Occurrence of male phenotype in genotypic females with congenital virilizing adrenal hyperplasia," American Journal of Medical Genetics, vol. 34, no. 3, pp. 406-412, 1989. 
[8] J. Y. Gillenwater, A. W. Wyker, M. Birdsong, and W. N. Thornton, "Adrenogenital syndrome producing female pseudohermaphroditism with a phallic urethra," Journal of Urology, vol. 103, no. 4, pp. 500-504, 1970.

[9] D. N. Ruble and C. L. Martin, "Gender development," in Handbook of Child Psychology, W. Damon and N. Eisenberg, Eds., vol. 3 of Social, Emotional, and Personality Development, pp. 933-1016, John Wiley \& Sons, New York, NY, USA, 5th edition, 1998.

[10] A. B. Dessens, F. M. E. Slijper, and S. L. S. Drop, "Gender dysphoria and gender change in chromosomal females with congenital adrenal hyperplasia," Archives of Sexual Behavior, vol. 34, no. 4, pp. 389-397, 2005.

[11] P. Wilson, C. Sharp, and S. Carr, "The prevalence of gender dysphoria in Scotland: a primary care study," British Journal of General Practice, vol. 49, no. 449, pp. 991-992, 1999.

[12] H. F. L. Meyer-Bahlburg, C. Dolezal, S. W. Baker, and M. I. New, "Sexual orientation in women with classical or nonclassical congenital adrenal hyperplasia as a function of degree of prenatal androgen excess," Archives of Sexual Behavior, vol. 37, no. 1, pp. 85-99, 2008.

[13] U. Kuhnle and W. Krahl, "The impact of culture on sex assignment and gender development in intersex patients," Perspectives in Biology and Medicine, vol. 45, no. 1, pp. 85-103, 2002.

[14] M. J. Baum, "Mammalian animal models of psychosexual differentiation: when is "translation" to the human situation possible?" Hormones and Behavior, vol. 50, no. 4, pp. 579-588, 2006.

[15] P. Cohen-Kettenis, "Psychological long-term outcome in intersex conditions," Hormone Research, vol. 64, no. 2, pp. 27 30, 2005.

[16] D. T. Wyatt, F. I. Chasalov, A. B. Granoff, and S. L. Blethen, "Complete masculinization of the external genitalia in a genetic female with non-salt-losing 21-hydroxylase deficiency," Journal of Pediatric Endocrinology, vol. 2, no. 1, pp. 35-38, 1986.

[17] V. Sripathi, S. Ahmed, N. Sakati, and A. Al-Ashwal, "Gender reversal in 46XX congenital virilizing adrenal hyperplasia," British Journal of Urology, vol. 79, no. 5, pp. 785-789, 1997.

[18] J. Woelfle, W. Hoepffner, W. G. Sippell et al., "Complete virilization in congenital adrenal hyperplasia: clinical course, medical management and disease-related complications," Clinical Endocrinology, vol. 56, no. 2, pp. 231-238, 2002.

[19] H. W. Jones Jr., "The saga of untreated congenital adrenal hyperplasia," Journal of Pediatric Endocrinology and Metabolism, vol. 17, no. 11, pp. 1481-1484, 2004.

[20] J. Money and J. Dalery, "Iatrogenic homosexuality: gender identity in seven 46,XX chromosomal females with hyperadrenocortical hermaphroditism born with a penis, three reared as boys, four reared as girls," Journal of Homosexuality, vol. 1, no. 4, pp. 357-371, 1976.

[21] H. F. L. Meyer-Bahlburg, R. S. Gruen, M. I. New et al., "Gender change from female to male in classical congenital adrenal hyperplasia," Hormones and Behavior, vol. 30, no. 4, pp. 319332, 1996.

[22] O. Moore, S. Kreitler, M. Ehrenfeld, and N. Giladi, "Quality of life and gender identity in Parkinson's disease," Journal of Neural Transmission, vol. 112, no. 11, pp. 1511-1522, 2005.

[23] V. I. Pikler and C. Brown, 'Cancer patients' and partners' psychological distress and quality of life: influence of gender role," Journal of Psychosocial Oncology, vol. 28, no. 1, pp. 4360, 2010.
[24] H. A. Delemarre-Van de Waal and P. T. Cohen-Kettenis, "Clinical management of gender identity disorder in adolescents: a protocol on psychological and paediatric endocrinology aspects," European Journal of Endocrinology, Supplement, vol. 155, no. 1, pp. S131-S137, 2006.

[25] T. H. Johannsen, C. P. L. Ripa, E. L. Mortensen, and K. M. Main, "Quality of life in 70 women with disorders of sex development," European Journal of Endocrinology, vol. 155, no. 6, pp. 877-885, 2006.

[26] C. P. Houk and P. A. Lee, "Approach to assigning gender in 46,XX congenital adrenal hyperplasia with male external genitalia: replacing dogmatism with pragmatism," Journal of Clinical Endocrinology and Metabolism, vol. 95, no. 10, pp. 4501-4508, 2010. 